\title{
Relationship between Parental Capacity and Quality of Life of Children with Cancer
}

\author{
Siti Aisyah Dalimunthe*, Sri Sofyani, Gema Nazri Yanni
}

*sitiaisyahd@gmail.com

Department of Child Health, Faculty of Medicine, University of Sumatera Utara, Medan, Indonesia J1. Dr. Mansyur No.5 Padang Bulan, Medan Baru, Medan, North Sumatera, Indonesia

\begin{abstract}
The objectives of this research was to assess the relationship between parental capacity and quality of life of children with cancer. Parental capacity, such as overprotection (OP), perception of child vulnerability (PCV), and parenting stress (PS), can affect the relationship between parents and their children with cancer. It influences children's emotional, behavioral, and social functions. This research was an analytical crosssectional research carried out to 74 children in Haji Adam Malik Hospital Medan from November - December 2020. Interviews were conducted to assess children's quality of life by PedsQL and parental capacity with Kolmogorov Smirnov test. Correlation tests were done by Pearson and Spearman analysis. The mean value of PS was 103.32. The median score of OP was $48(28-68)$, PCV was $17(10-22)$, and children's quality of life was $77.88(50.55-98.15)$. There was no significant relationship between OP $(p=0.469)$ and PCV $(p=$ 0.781 ) with quality of life. However, significant relationship was observed between PS and quality of life (p $<0.001)$ of children with cancer.
\end{abstract}

Keywords: Parental capacity; pediatric quality of life; cancer

\section{Introduction}

Cancer is one of the leading causes of death in children worldwide. The incidence tends to increase over time. International Association of Cancer Registries stated that there have been at least over 385 thousand incidences of cancer at the age of $0-19$ years old in the last decade (Steliarova et al., 2017). High morbidity and mortality rates in children with chronic medical conditions, such as cancer, often cause psychosocial difficulties in adults (Sitaresmi et al., 2008). Psychological pressure from parents to contain their emotions can be manifested as anxiety, worries, sadness, and even depression.

Wolfe et al. reported that parents taking care of children with chronic medical conditions had higher risk of having psychological distress, hence having maladaptive parental behavior (Wolfe et al., 2014) There are three parental capacity variables, such as overprotection (OP), perception of child vulnerability (PCV), and parenting stress (PS). Overprotection (OP) is a parental attitude that is very supervising, difficult to part from their children, unable to let the children to be independent, and often very controlling (Bourdeau et al., 2007; Carpentier et al., 2008) Perception of child vulnerability (PCV) is a parenting style that takes children as being very sick and vulnerable (Forsyth et al., 1996). Parenting stress (PS) is a stress that occur due to the relationship between parents and their sick children, where their different characteristics also cause the occurring stress (Wolfe et al., 2014; Hullman et al., 2010) Studies have shown that high OP, PCV, and PS values 
can negatively affect children, causing bad emotional, behavioral, and social functions (Mullins et al., 2007).

Health related quality of life (HRQOL) describes the perception of health level of one individual after disease diagnosis and treatment from the individual, as well as the family (Davis et al., 2006). Studies showed that there were cases of younger children with cancer having lower quality of life due to anxiety about disease procedural, medication, and communication (Sitaresmi et al., 2008). Parental psychological pressure, coming from the difficulties to cope with emotions and cognitions that can manifest as anxiety, worries, sadness, or depression, contributes to the quality of life and well-being of their children with cancer.

Nowadays, there are many available scales that can clinically help assessing impaired parentchild relationship. However, only little data is available to validate those scales. The validity of the data is important, because those scales are able to provide different preventive, diagnostics, and therapeutic strategies for primary health care providers in supporting children's awareness of their health, diseases, and development of the personal autonomy (Thomasgard, 1998). Therefore, it is important to provide family-based interventions that target parental behavior in children population with chronic conditions, for instance children group with cancer. The intervention is also expected to encourage parents to adapt to their children living with medical chronic condition (Steliarova et al., 2017). This research studied about parental capacity and the relationship with the quality of life of children with cancer.

\section{Methods}

This was an analytical cross-sectional study to assess the variables of parental capacity and the effects to quality of life of children with cancer. The research was conducted in pediatric hematology-oncology outpatient and inpatient unit in Haji Adam Malik hospital Medan from November to December 2020.

Research samples were children with cancer who were receiving treatment in pediatric hematology-oncology outpatient and inpatient unit in Haji Adam Malik hospital Medan and having their parents or guardians to accompany them during treatment throughout year 2020. The research subjects met the inclusion and exclusion criteria. They were selected by consecutive sampling method. Inclusion criteria were children with cancer aged $<18$ years old, whose parents and guardians were able to completely fill in the questionnaire, and they agreed to become the subjects in the research by signing the consent form. Exclusion criteria were children experiencing decreased in consciousness or being in critical or terminal conditions, and receiving palliative care. Then, children and parents or guardians who consumed sedative drugs during the research, and experienced organic mental disorders or significant development impairment.

Interviews were conducted to obtain demographic data of research subjects, such as gender, age, type of cancer, duration of diagnosis, type of patients - whether new or relapse patients, and quality of life assessment by using PedsQL. Whereas for the parents or guardians, there were assessment for their quality of life, and values of overprotection (OP), perception of child vulnerability (PCV), and parenting stress (PS). 


\subsection{Research ethics}

Parents of the research subjects were given explanations about the research and they were asked for consent to be involved in the study. This study was approved by Health Research Ethical Committee, Medical Faculty of Sumatera Utara (No. 750/KEP/USU/2020).

\subsection{Data analysis}

Data collected was analyzed by using a computerized software system. Univariate analysis was carried out for research subject characteristic data, by presenting categoric data with percentage, while numerical data was presented in average and standard deviation, as well as median with minimum and maximum values. Bivariate analysis was used to assess the correlations among variables of parental capacity with quality of life. Pearson correlation was used for normally distributed data, otherwise Spearman test was carried out. The significance level and confidence interval in this study were $\mathrm{p}<0.05$ and $95 \%$ respectively.

\section{Results}

\subsection{Research subject data characteristic}

This research was followed by 74 pediatric patients with cancer. There were more male $(51.4 \%)$ than female patients. The average age of patients was 8.39 years old, while the average age of parents was 38.32 years old. There were 32 parents $(43.2 \%)$ who had graduated from universities and 30 parents $(40.5 \%)$ were high school graduates. The majority of research subjects suffered from hematologic cancer $(83.8 \%)$ and the rest $(16.2 \%)$ suffered from solid tumor cancers. There were 8 subjects (10.8\%) who had been diagnosed with cancer for $<6$ months, 20 subjects (27\%) for 6 months -1 year, 24 subjects (32.4\%) for $>1-2$ years, and 22 subjects $(29.8 \%)$ for $>2$ years. Among all the subjects, 64 patients ( $86.5 \%$ ) were newly diagnosed patients, where 10 of them $(13.5 \%)$ were relapse cases. The demographic characteristic of research subjects and their parents is shown in Table 1.

Table 1. Research subject characteristic data

\begin{tabular}{lc}
\hline Demographic Characteristics & $\mathbf{n}=\mathbf{7 4}$ \\
\hline Gender, $\mathrm{n}(\%)$ & $38(51.4)$ \\
Male & $36(48.6)$ \\
Female & $8.39(4.24)$ \\
Children's age, average (SD), years old & $38.32(7.39)$ \\
Parents' age, average (SD), years old & \\
Education level of parents, n (\%) & $4(5.4)$ \\
$\quad$ Primary school & $8(10.8)$ \\
Secondary school & $30(40.5)$ \\
High school & $32(43.2)$ \\
University graduates & \\
Type of cancer, n (\%) & $62(83.8)$ \\
Hematology & $12(16.2)$ \\
Solid tumors & \\
Duration of diagnosis, n $(\%)$ & $8(10.8)$ \\
$\quad<6$ months & $20(27)$ \\
6 months -1 year &
\end{tabular}




\begin{tabular}{ll}
\hline$>1-2$ years & $24(32.4)$ \\
$>2$ years & $22(29.8)$ \\
Type of patient, $\mathrm{n}(\%)$ & \\
New & $64(86.5)$ \\
Relapse & $10(13.5)$ \\
\hline
\end{tabular}

3.2. Statistics of parental capacity variables and quality of life of children with cancer

Table 2 shows the average and standard deviation (SD), and median and range (min-max) of Kolmogorov Smirnov test for parental capacity variables, such as OP, PCV, and PS scores, as well as quality of life of both parents and children. Data was normally distributed and analyzed by Pearson correlation analysis. The average score of parental stress (PS) was 103.32, which means that the score met the criteria of parental stress. While the quality of life of parents was 74.07 that indicated parents had good quality of life. In this research, overprotection (OP) score was at median 48 , in the range of 28 to 68 ( $\min -\max$ ). The median of child vulnerability perception (PCV) was 17 , with a range of 10 to $22(\min -\max )$. The median of quality of life of children was 77.88 , with a range of 50.55 to $98.15(\min -\max )$.

Table 2. Statistics of OP, PCV, PS of parents and quality of life

\begin{tabular}{lcc}
\hline Parameter & Average (SD) & P value \\
\hline Parental stress (PS) & $103.32(18.54)$ & $0.200^{*}$ \\
Parent's quality of life & $74.07(16.24)$ & $0.200^{*}$ \\
\hline & Median (range) & P value \\
\hline Overprotection (OP) score & $48(28-68)$ & $0.042^{*}$ \\
Perception of child vulnerability (PCV) score & $17(10-22)$ & $<0.001^{*}$ \\
Children's quality of life & $77.78(50.55-98.15)$ & $0.046^{*}$ \\
\hline
\end{tabular}

${ }^{*}$ Pearson correlation analysis

3.3. Relationship between parental capacity variables and quality of life of children with cancer

Table 3 displays the correlation test between parental capacity and quality of life of children with cancer. There was no significant relationship between overprotection (OP) and children's quality of life $(p=0.469)$. Similarly, perception of children vulnerability (PCV) was also not significantly correlated to the quality of life, with $p=0.781$. Meanwhile, parental stress (PS) was significantly correlated to quality of life of children, with $p<0.001$ and correlation value of 0.409 . This means that the higher the parental stress, the lower the quality of life of children.

Table 3. Correlation between parental capacity variables and children's quality of life

\begin{tabular}{lcc}
\hline \multirow{2}{*}{ Parameter } & \multicolumn{2}{c}{ Children's quality of life } \\
\cline { 2 - 3 } & r & P value \\
\hline Overprotection (OP) & 0.085 & $0.469^{*}$ \\
Perception of child vulnerability (PCV) & 0.033 & $0.781^{*}$ \\
Parental stress (PS) & 0.409 & $<0.001^{*}$ \\
\hline
\end{tabular}

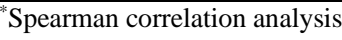




\section{Discussion}

In this research, there were more male pediatric patients (51.4\%) than female. The study done by Liu et al., collecting data from International Incidence of Childhood Cancer, concluded that boys tends to be more prone than girls (Liu et al., 2019). The average age of patients in this research was 8.39 years old. The data from International Agency for Research on Cancer in year 2010, in the study by Steliarova et al. stated that around $11.4 \%$ of children worldwide aged $0-14$ years old were diagnosed with cancer (Steliarova et al., 2017). Moreover, the study done by Hilda et al. in Haji Adam Malik hospital Medan in year 2012 reported the average age of research subjects with cancer was 9.9 years old (Hilda et al., 2015).

The majority of cancer type in this research was hematologic cancer, with 62 subjects (83.8\%) diagnosed. According to International Association of Cancer Registries in the study by Steliarova et al. hematologic cancer was the most commonly found cancer type in children worldwide, at around 36\% of total cases (Steliarova et al., 2017). Now, Hilda et al. reported 69.6\% of hematologic cancer cases in their study taking place in Haji Adam Malik hospital Medan in year 2012 (Hilda et al., 2015). As for duration of diagnosis, most patients (32.4\%) had been diagnosed with cancer for about 1 to 2 years. Alves, Guirardello, and Kurashima from Brazil stated that there was relationship between the time of first diagnosis and stress factor, where parents would have higher level of stress and anxiety at early diagnosis. Parents whose children had been diagnosed for over a period of time would have gone through a period of adaptation to the disease (Alves, Guirardello, and Kurashima, 2013). In this research, most subjects (86.5\%) were newly diagnosed patients with cancer, whereas 10 subjects (13.5\%) were relapse cases. According to the data from Childhood Cancer Survivor Study by Wasilewski-Mas et al., the overall probability of relapses of cancer in children was $4.4 \%$ in the first 5 years. It would increase to $6.2 \%$ in 10 -year time, which was influenced by multifactorial factors, such as the severity of previous diseases, child and family characteristics, and previous treatment history (Wasilewski-Mas et al., 2009).

Parental stress (PS) score in this research was 103.32, which indicated that the score met the criteria of parental stress. Hung, $\mathrm{Wu}$, and Yeh from China compared the average parental stress score of patients with cancer to patients with disabilities, and the result showed that parents of children with cancer had higher average of PS, at an average of 118.3 (Hung, Wu, and Yeh, 2004). As for quality of life of parents, the average score in this research was 74.07 , indicating parents had good quality of life. Rensen et al. conducted a study and reported an average of 80.1 and 79.1 quality of life scores in the fathers and mothers of children with cancer respectively (Rensen et al., 2019). Quality of life score above 70 means that subjects had good quality of life.

There was an increase in overprotection (OP) score in the research subjects, with a median of 48 , within the range of 28 to 68 ( $\min -\max$ ). The study done by Hullman et al. about the relationship between parental overprotection and HRQOL in pediatric cancer reported an average OP score of 32 in parents of children with cancer, with minimum and maximum score of 17 and 49 respectively. The perception of child vulnerability (PCV) score was at median of 17 in this study, where the minimum was 10 and the maximum was 22 . Whereas, Hullman et al., (2010) reported an average score of PCV of 7, with min - max value of 0 - 18 (Hullman et al., 2010).

The median value of quality of life of children was 77.88, with minimum value of 50.55 and maximum of 98.15 . The study done by Hilda et al. reported the average quality of life of children with cancer was $42.1 \%$ (Hilda et al., 2015). This research showed no significant relationship between OP and quality of life of children $(\mathrm{p}=0.469)$. Similarly, there was no relationship between 
PCV and quality of life with $\mathrm{p}=0.781$. Mullins et al. also reported no relationship between parental overprotection and quality of life of children with asthma. They also conducted study with diabetic pediatric patients and reported no significance between OP and depression symptoms in children (Mullins et al., 2007). However, Hullman et al. reported that the increases in parental OP and PCV were correlated with the decrease in quality of life of children. However, by controlling the characteristics of children and parents, as well as disease parameters, there would be adjustments to children and their quality of life towards their parent's parental capacity of OP and PCV variables (Hullman et al., 2010).

In the assessment of parental stress, there was a significant relationship to quality of life of children observed $(\mathrm{p}<0.001 ; \mathrm{r}=0.409)$. The metanalysis study conducted by Bakula et al. with 14 researches, consisted of 1646 parents of children with cancer, showed moderate scale of correlation between parental stress (PS) and quality of life of children $(r=0.23 ; p<0.001)$. This has stated that psychosocial functions of parents contributed to children's psychosocial functions in childhood cancer cases (Bakula et al., 2020). Given the importance of parental function theory in understanding children's function, the psychosocial aspects of parents become an important variable to understand the quality of life of children after cancer diagnosis (Hullman et al., 2010).

\section{Conclusion}

There was no significant relationship between overprotection (OP) score and quality of life of children. There was also no significance between perception of children vulnerability (PCV) and quality of life. There was, however, a significant relationship between parental stress (PS) and quality of life of children.

\section{Acknowledgements}

The author would like to thank all the staff in the Faculty of Medicine, Universitas Sumatera Utara for the extensive support during the study.

\section{References}

Alves DF, Guirardello ED, Kurashima AY. Stress related to care: the impact of childhood cancer on the lives of parents. Revista Latino-Americana de Enfermagem. 2013;21:356-62

Bakula DM, Sharkey CM, Perez MN, Espeleta HC, Gamwell KL, Baudino M, dkk. The relationship between parent distress and child quality of life in pediatric cancer: A meta-analysis. Journal of pediatric nursing. 2020;50:14-9

Bourdeau TL, Mullins LL, Carpentier MY, Colletti CJ, Wolfe-Christensen C. An examination of parenting variabels and child self-care behavior across disease groups. Journal of Developmental and Physical Disabilities. 2007; 19:125-34

Carpentier MY, Mullins LL, Wolfe-Christensen C, Chaney JM. The relationship of parent self-focused negative attributions to ratings of parental overprotection, perceived child vulnerability, and parenting stres. Families, Systems, \& Health. 2008; 26:147-63

Davis E, Waters E, Mackinnon A, Reddihough D, Graham HK, Mehmet-Radji O, et al. Paediatric quality of life instruments: a review of the impact of the conceptual framework on outcomes. Developmental medicine and child neurology. 2006; 16:311-8

Forsyth BW, Horwitz SM, Leventhal JM, Bruger J, Leaf PJ. The child vulnerability scale: an instrument to measure parental perceptions of child vulnerability. Journal of pediatric psychology. 1996; 21:89-101

Hilda H, Lubis B, Hakimi H, Siregar OR. Quality of life in children with cancer and their normal siblings. Pediatrica Indonesiana. 2015; 55:243-7 
Hullmann SE, Wolfe C, Ryan JL, Fedele DA, Rambo PL, Chaney JM, et al. Parental overprotection, perceived child vulnerability, and parenting stres: A cross-illness comparison. Journal of clinical psychology in medical settings. 2010; 17:357-65

Hullmann SE, Wolfe C, Meyer WH, McNall RY, Mullins LL. The relationship between parental overprotection and healthrelated quality of life in pediatric cancer: the mediating role of perceived child vulnerability. Quality of Life Research. 2010; 19:1373-80

Hung JW, Wu YH, Yeh CH. Comparing stress levels of parents of children with cancer and parents of children with physical disabilities. Psycho-Oncology: Journal of the Psychological, Social and Behavioral Dimensions of Cancer. 2004;13:898-903

Liu Z, Yang Q, Cai N, Jin L, Zhang T, Chen X. Enigmatic differences by sex in cancer incidence: evidence from childhood cancers. American journal of epidemiology. 2019;86:1130-5

Mullins LL, Wolfe-Christensen C, Hoff Pai AL, Carpentier MY, Gillaspy S, et al. The relationship of parental overprotection, perceived child vulnerability, and parenting stres to uncertainty in youth with chronic illness. Journal of pediatric psychology. 2007; 32:973-82

Rensen N, Steur LM, Schepers SA, Merks JH, Moll AC, Kaspers GJ, dkk. Determinants of health-related quality of life proxy rating disagreement between caregivers of children with cancer. Quality of Life Research. 2019;9:901-12

Sitaresmi MN, Mostert S, Gundy CM, Veerman AJ. Health-related quali Cty of life assessment in Indonesian childhood acute lymphoblastic leukemia. Health and quality of life outcomes. 2008; 6:96-04

Steliarova FE, Colombet M, Ries LA, Moreno F, Dolya A, Bray F, et al. International incidence of childhood cancer 200110: a population-based registry study. The Lancet Oncology. 2017; 6:719-31

Thomasgard M. Parental perceptions of child vulnerability, overprotection, and parental psychological characteristics. Child Psychiatry and Human Development. 1998; 1:223-40

Wasilewski-Masker K, Liu Q, Yasui Y, Leisenring W, Meacham LR, Hammond S, dkk. Late recurrence in pediatric cancer: a report from the Childhood Cancer Survivor Study. Journal of the National Cancer Institute. 2009;101:1709-20

Wolfe C, Fedele DA, Kirk K, Mullins LL, Lakshmanan Y, Wisniewski AB. Caregivers of children with a disorder of sex development: associations between parenting capacities and psychological distres. Journal of pediatric urology. 2014; 10:538-43 